\title{
Characterization and Electrocatalytic Performance of Molasses Derived Co-Doped (P, N) and Tri-Doped (Si, P, N) Carbon for the ORR
}

\author{
Samantha Macchi ${ }^{1}$ (D) Fumiya Watanabe ${ }^{2}$, Tito Viswanathan ${ }^{1}$ and Noureen Siraj ${ }^{1, *(D)}$ \\ 1 Department of Chemistry, University of Arkansas at Little Rock, 2801 S. University Ave, \\ Little Rock, AR 72204, USA; spmacchi@ualr.edu (S.M.); txviswanatha@ualr.edu (T.V.) \\ 2 Center for Integrative Nanotechnology Sciences, University of Arkansas at Little Rock, 2801 S. University Ave, \\ Little Rock, AR 72204, USA; fxwatanabe@ualr.edu \\ * Correspondence: nxsiraj@ualr.edu; Tel.: +1-501-916-6544
}

Citation: Macchi, S.; Watanabe, F.;

Viswanathan, T.; Siraj, N.

Characterization and Electrocatalytic Performance of Molasses Derived Co-Doped (P, N) and Tri-Doped (Si, P, N) Carbon for the ORR. Electrochem 2021, 2, 311-322. https://doi.org/ 10.3390/electrochem2020022

Academic Editor: Masato Sone

Received: 18 March 2021

Accepted: 26 May 2021

Published: 2 June 2021

Publisher's Note: MDPI stays neutral with regard to jurisdictional claims in published maps and institutional affiliations.

Copyright: (c) 2021 by the authors. Licensee MDPI, Basel, Switzerland. This article is an open access article distributed under the terms and conditions of the Creative Commons Attribution (CC BY) license (https:/ / creativecommons.org/licenses/by/ $4.0 /)$

\begin{abstract}
There is a growing need to develop sustainable electrocatalysts to facilitate the reduction of molecular oxygen that occurs at the cathode in fuel cells, due to the excessive cost and limited availability of precious metal-based catalysts. This study reports the synthesis and characterization of phosphorus and nitrogen co-doped carbon (PNDC) and silicon, phosphorus, and nitrogen tridoped carbon (SiPNDC) electrocatalysts derived from molasses. This robust microwave-assisted synthesis approach is used to develop a low cost and environmentally friendly carbon with high surface area for application in fuel cells. Co-doped PNDC as well as tri-doped SiPNDC showed Brunauer-Emmet-Teller (BET) surface areas of 437 and $426 \mathrm{~m}^{2} \mathrm{~g}^{-1}$, respectively, with well-developed porosity. However, examination of X-ray photoelectron spectroscopy (XPS) data revealed significant alteration in the doping elemental composition among both samples. The results obtained using rotating disk electrode (RDE) measurements show that tri-doped SiPNDC achieves much closer to a 4-electron process than co-doped PNDC. Detailed analysis of experimental results acquired from rotating ring disk electrode (RRDE) studies indicates that there is a negligible amount of peroxide formation during ORR, further confirming the direct-electron transfer pathway results obtained from RDE. Furthermore, SiPNDC shows stable oxygen reduction reaction (ORR) performance over 2500 cycles, making this material a promising electrocatalyst for fuel cell applications.
\end{abstract}

Keywords: electrocatalyst; oxygen reduction reaction; doped carbon; fuel cell; renewable energy

\section{Introduction}

As the world population is growing and similarly consuming more non-renewable energy sources, a major sector of research is dedicated to seeking alternative methods of storing and transferring energy. Fuel cells are just one of the many types of energy conversion devices currently on the market. These cells utilize molecular oxygen and a fuel source (hydrogen, methanol, etc.) to produce electrical energy and water vapor as a byproduct [1]. There are several fundamental problems that exist within this technology; one being that the cathodic reaction where the reduction of oxygen occurs is very slow under normal conditions [2,3]. To allow for commercial exploitation of these devices, a suitable catalyst must be used to speed up the reaction. Platinum is the most commonly used catalyst, as it is efficient and exhibits low overpotential values [4]. However, platinum is an expensive and rare metal. Thus, many modern research studies investigate the use of non-metallic catalysts for use in oxygen reduction reaction (ORR) fuel cells [5,6]. Alternative electrocatalysts such as metal oxides [7,8], graphene and graphene oxide [9], and other carbon-based materials [6] are currently being investigated for use in fuel cell devices.

Carbon-based catalysts have been widely studied as electrocatalyst candidates for fuel cells due to the low cost, and readily available nature of the element. A vast number 
of carbon forms have also been explored in this area such as carbon nanotubes [10-13], aerogels [14-16], activated carbon [17,18], and amorphous carbon [19]. Amorphous carbon has grown in popularity due to the ease of synthesis as compared to other forms of carbon. Moreover, it is also possible to synthesize these materials from abundant and inexpensive precursors, such as renewable plant-based sources. There are many literature reports of the conversion of plant products such as cellulose [20-22], honey [23], and soy [24] into useful carbon materials. Thus, all the aforementioned characteristics of carbon materials allow electrocatalysts to be produced at an exceptionally low cost, making their large-scale production more appealing than other catalysts.

In recent years, researchers have investigated the significance of doping amorphous carbon with heteroatoms in relation to the effect on its electrochemical properties $[25,26]$. This involves the introduction of a small number of defects into a carbon matrix. The doping of amorphous carbons with many different elements has been reported, such as with nitrogen, boron, sulfur, and phosphorus $[25,27,28]$. These atoms serve to change the properties of the material by altering the band gap, conductivity, and electrochemical characteristics [29]. Researchers also seek to determine the optimal doping elemental composition for electrocatalytic performance. This is achieved by doping with one, two, or even three different elements [25,30,31]. Phosphorus and nitrogen co-doping of carbon is often employed for energy storage applications such as fuel cell and supercapacitors [25,27]. Recently, it has been shown that introducing silicon with other heteroatoms such as nitrogen or phosphorus can enhance the ORR activity of carbon materials due to alteration in the charge distribution and energetic characteristics of the material [32]. Specifically, co-doping with silicon and nitrogen [33] or silicon and phosphorus [34] has been shown to exhibit synergistic enhancement of electrocatalysis. Tri-doping has allowed further enhancement of catalytic properties of carbon $[23,35,36]$. This work seeks to analyze the effect of co-doping versus tri-heteroatom doping in carbon materials derived from molasses by investigating the structural, chemical and electrochemical changes associated with each.

Herein, we provide a rapid, easy synthesis of molasses-based phosphorus and nitrogen co-doped carbon (PNDC) and silicon, phosphorus, and nitrogen tri-doped carbon (SiPNDC) to investigate the effect of dual- versus tri- heteroatom doping on physical and electrochemical properties. The surface morphology and porosity are examined in detail as well as the surface elemental composition which greatly impacts the electrocatalyst performance. Both doped carbon materials are electrochemically characterized using rotating disk electrode (RDE) measurements to determine the number of electrons transferred during ORR. Rotating ring disk electrode (RRDE) studies are employed to investigate the mechanism of electron transfer of ORR. This work highlights for the first time a comparison between co-doped PNDC with tri-doped SiPNDC material from a renewable molasses precursor for use as an ORR electrocatalyst.

\section{Materials and Methods}

\subsection{Materials and Synthesis}

Molasses (Grandma's) was purchased from a grocery store in Little Rock, AR, USA. Ammonium polyphosphate (APP) was acquired from JLS Chemical Inc, Pomona, CA, USA. Polydimethylsiloxane (PDMS) was a gift from Clearco Products Co., Inc., Bensalem, PA, USA. Potassium hydroxide $(\mathrm{KOH})$ and ethanol were purchased from VWR (Radnor, PA, USA). Nafion was purchased from Bean Town Chemical, Hudson, NH, USA. All chemicals were used as received. Ultrapure deionized water $(18.2 \mathrm{M} \Omega \mathrm{cm})$ was obtained through Elga (PURELAB, Woodridge, IL, USA) water filtration system. Ultrahigh purity nitrogen gas $\left(\mathrm{N}_{2}\right)$ and oxygen gas $\left(\mathrm{O}_{2}\right)$ were obtained from AirGas (Little Rock, AR, USA). Glassy carbon electrode (MF-2012) was purchased from BASi, West Lafayette, IN, USA. RDE and Pt ring-disk electrode assembly (AFE6RIPT) RRDE were purchased from Pine Instrument Company (Grove Cite, PA, USA). Aluminum sample mounts and double-sided carbon tape were used to prepare doped carbon samples for scanning electron microscopy (SEM) imaging. 
PNDC and SiPNDC were prepared via a microwave-assisted technique reported elsewhere $[27,37,38]$. To prepare SiPNDC, a $2.0 \mathrm{~g}$ sample of molasses was blended well in a mortar and pestle with APP (1.2 g) and $0.6 \mathrm{~g}$ PDMS. Similarly, a mixture for PNDC was prepared without addition of PDMS (Table 1). This mixture was transferred to a boron nitride crucible, covered with a similar crucible, and placed in an aluminum oxide box; the box was then placed in a conventional microwave oven. The mixture was subjected to microwave irradiation for $35 \mathrm{~min}$ at $2.45 \mathrm{GHz}$ and $1.25 \mathrm{KW}$ power. Then the product was allowed to cool in the microwave to room temperature. After cooling, it was weighed, powdered using mortar and pestle, and stored in a desiccator for further use. A greater product yield was obtained for SiPNDC in comparison to PNDC.

Table 1. Synthetic conditions for preparation of PNDC and SiPNDC.

\begin{tabular}{ccccc}
\hline Sample & Weight Molasses $(\mathbf{g})$ & Weight APP $(\mathbf{g})$ & Weight PDMS $(\mathbf{g})$ & Yield $(\mathbf{g})$ \\
\hline PNDC & 2.00 & 1.2 & 0.00 & 0.251 \\
SiPNDC & 2.00 & 1.2 & 0.60 & 0.312 \\
\hline
\end{tabular}

\subsection{Characterization}

A Thermo K-Alpha X-ray photoelectron spectroscopy (XPS) system was used to determine the surface elemental composition of dried powder samples of PNDC and SiPNDC. Survey scans of each material were performed on three different spots of the doped carbon surface. A JEOL (Tokyo, Japan) JSM-7000F SEM was utilized to determine the morphology of materials. ASAP 2020 Micromeritics Surface Area and Porosity Analyzer (Norcross, GA, USA) with Brunauer-Emmett-Teller (BET) method was employed to analyze the surface area and pore size of materials via nitrogen adsorption/desorption studies at a temperature of 77 K. A Raman spectroscopy instrument (Horiba Jobin Yvon LabRam 800, Kyoto, Japan) was utilized to analyze defect properties of the catalysts. A $514.5 \mathrm{~nm}$ laser source was used with $200 \mu \mathrm{m}$ hole size and acquisition time of $10 \mathrm{~s}$.

Cyclic voltammetry (CV) studies were performed at room temperature using an EC Epsilon ${ }^{\mathrm{TM}}$ (Irving, TX, USA) potentiostat/galvanostat and a three-electrode system with $0.1 \mathrm{M} \mathrm{KOH}$ electrolyte in water. A glassy carbon electrode surface coated with active material (PNDC or SiPNDC) was used as the working electrode. $\mathrm{Hg} / \mathrm{HgO}$ and $\mathrm{Pt}$ wire were used as the reference electrode and as the counter electrode, respectively. Ten $\mu \mathrm{L}$ aliquots of a slurry suspension of $90 \%$ PNDC or SiPNDC and 10\% Nafion in ethanol were loaded onto the glassy carbon electrode surface and air dried, followed by the addition of another aliquot. Cyclic voltammograms were recorded from $-1000-0 \mathrm{mV}$ in $0.1 \mathrm{M} \mathrm{KOH}$ electrolyte. All measurements were performed at $100 \mathrm{mV} / \mathrm{s}$ in either $\mathrm{N}_{2}$ or $\mathrm{O}_{2}$ saturated electrolyte. RDE and RRDE were used as working electrodes using a Pine instruments Company bipotentiostat coupled with a MSRX electrode rotator (Pine) with a similar three electrode setup used in CV measurements, with a glassy carbon rotating electrode $\left(0.247 \mathrm{~cm}^{2}\right.$ surface area) coated with doped carbon material. RDE measurements were performed using various rotation speeds from 100-2500 rpm in an $\mathrm{O}_{2}$ saturated environment with $0.1 \mathrm{M}$ $\mathrm{KOH}$ at a scan rate of $50 \mathrm{mV} / \mathrm{s}$. Linear sweep voltammograms (LSV) with RDE were also recorded in an $\mathrm{N}_{2}$ saturated environment as a background for electron calculation. RRDE experiments were performed under similar conditions at $100 \mathrm{rpm}$ rotation.

\section{Results and Discussion}

\subsection{Physical Characterization}

SEM was performed on doped carbons to investigate their morphological features. The PNDC surface is sponge-like with spherical decorations of variant diameter (Figure 1a,b). There are large porous structures which are a product of gasses being released during microwave treatment. The SiPNDC surface is comprised of rough sheet-like structures, also with spherical decorations (Figure 1c,d). There is also the presence of some jagged rock-like structures which could be silicon dioxide formed during the carbonization process [23]. 


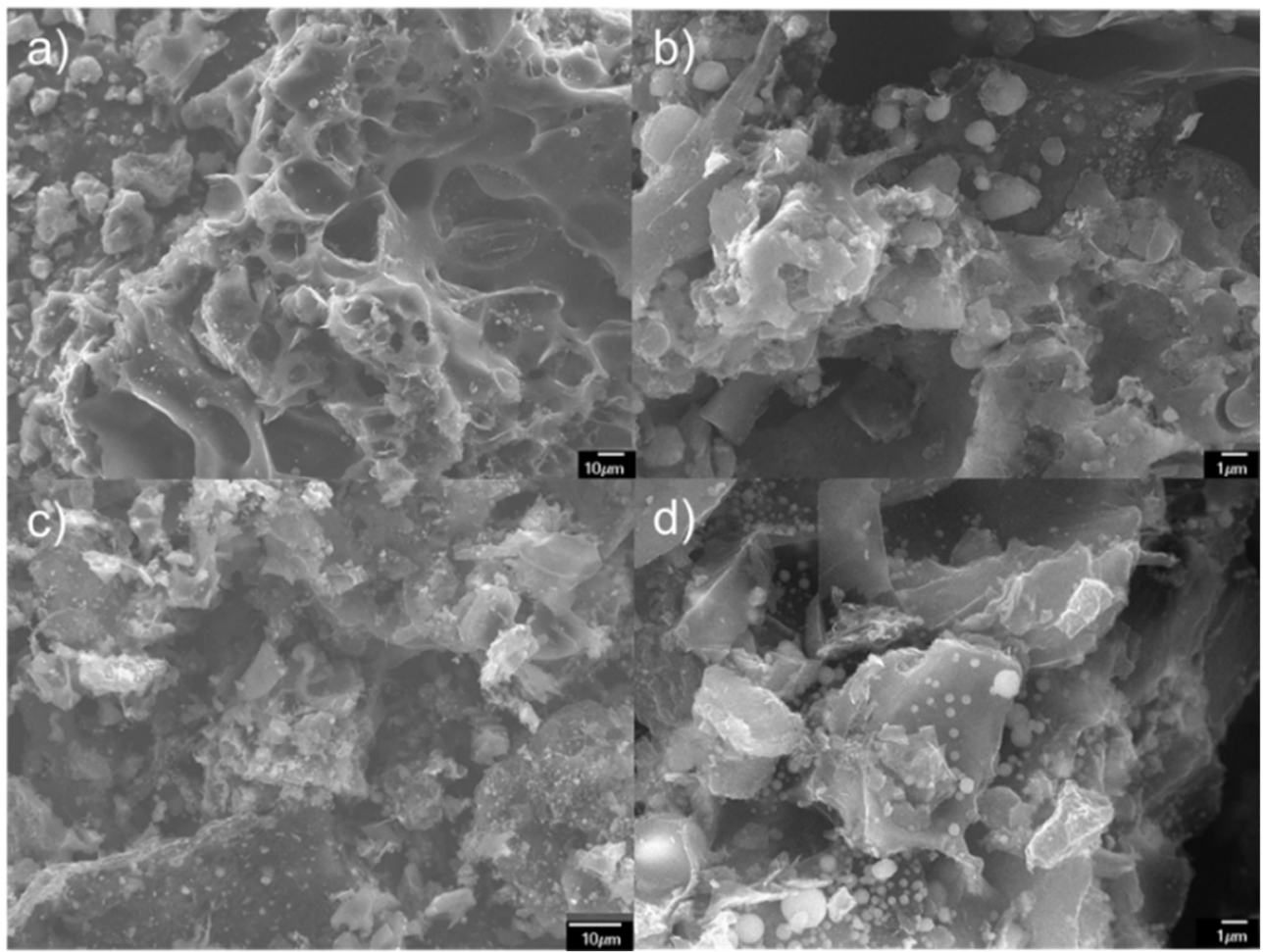

Figure 1. SEM images at $1000 \times$ and $5000 \times$ magnification for PNDC $(\mathbf{a}, \mathbf{b})$ and $\operatorname{SiPNDC}(\mathbf{c}, \mathbf{d})$.

Nitrogen adsorption and desorption analysis was performed on the samples using the BET method. Isotherms of both PNDC and SiPNDC are characteristic of type IV isotherms according to the IUPAC classification, which is indicative of monolayer-multilayer adsorption (Figure 2). This type of isotherm is characterized by prominent hysteresis at the upper range of $\mathrm{P} / \mathrm{P}_{0}$, due to capillary condensation in mesopores (2-50 $\mathrm{nm}$ width) [39]. The hysteresis loop is type H4 classified by IUPAC, which can be associated with narrow microporous ( $<2 \mathrm{~nm}$ width) features. The development of these pore structures is due to the microwave synthesis procedure, which heats the sample rapidly to very high temperature $\left(\sim 1000{ }^{\circ} \mathrm{C}\right)$, as determined by an infrared pyrometer. At these high temperatures, reducing gases are given off from the precursors which in turn leave nano-sized holes in the samples.
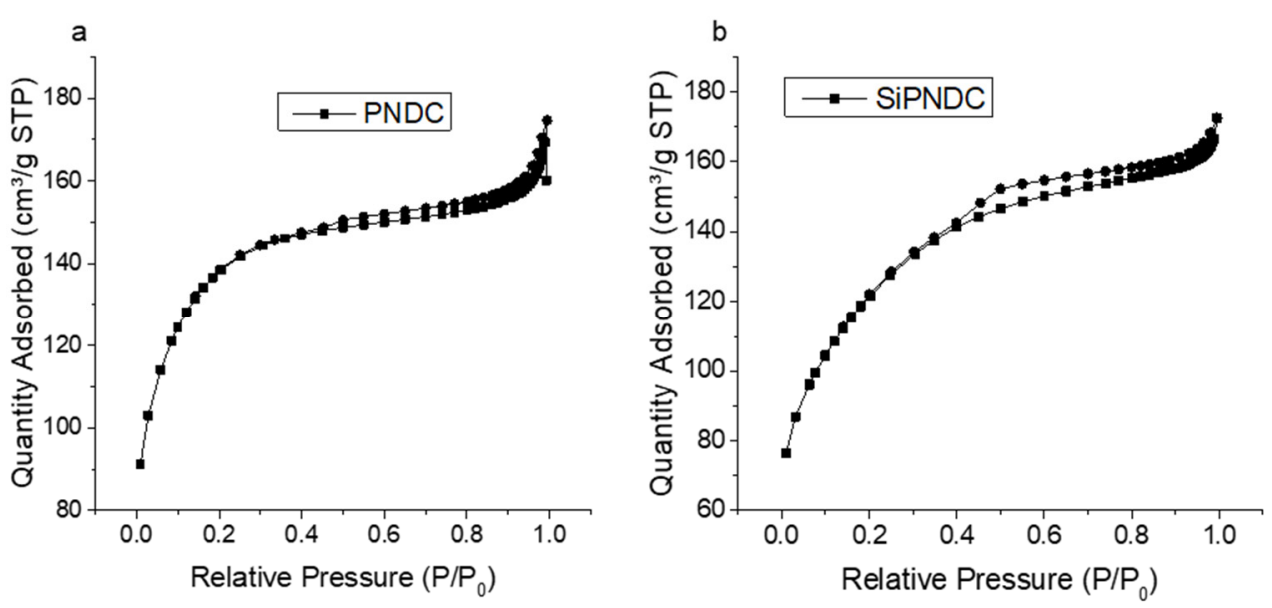

Figure 2. Nitrogen adsorption and desorption curves for (a) PNDC and (b) SiPNDC.

The BET surface areas of the two samples are remarkably similar $\left(437\right.$ and $426 \mathrm{~m}^{2} \mathrm{~g}^{-1}$ for PNDC and SiPNDC, respectively), indicating that the major constituent, molasses, is playing a larger role in surface development than the dopant materials (Table 2). The SiPNDC 
surface area, however, is slightly less than PNDC which is attributed to the formation of silicon dioxide deposits (not porous) that are formed in SiPNDC [23]. It is also worth noting that SiPNDC possesses smaller pore widths as well as a greater percentage of microporosity $(\sim 2.2 \mathrm{~nm})$ compared to PNDC $(2.6 \mathrm{~nm})$. This is attributed to the greater variation in reducing gases being formed during the production of SiPNDC in comparison to PNDC. The pore size distribution of PNDC and SiPNDC reveals a greater variance in pore size of SiPNDC compared to PNDC (Figure S1). This distribution of pore sizes is due to gas formation by precursors during microwave treatment. Possession of multiple pore structures can serve to enhance electrocatalytic behavior by decreasing ion transportation distance [40].

Table 2. Surface area and porosity analysis of doped carbon materials.

\begin{tabular}{ccc}
\hline & PNDC & SiPNDC \\
\hline BET Surface Area $\left(\mathrm{m}^{2} / \mathrm{g}\right)$ & 436.7 & 426.0 \\
Avg. pore width $(\mathrm{nm})$ & 2.55 & 2.19 \\
Total pore volume $\left(\mathrm{cm}^{3} / \mathrm{g}\right)$ & 0.26 & 0.23 \\
Micropore volume $\left(\mathrm{cm}^{3} / \mathrm{g}\right)$ & 0.03 & 0.06 \\
Mesopore volume $\left(\mathrm{cm}^{3} / \mathrm{g}\right)$ & 0.23 & 0.17 \\
\hline
\end{tabular}

XPS was utilized to investigate the surface elemental composition of PNDC and SiPNDC. Survey scans of both materials confirmed the presence of mostly carbon and oxygen with dopant percentages of phosphorus and nitrogen while significant silicon dopant was found only in SiPNDC as expected (Figure 3). Moreover, SiPNDC also contained a greater percentage of doping elements than PNDC (Table 3) indicating that the presence of silicon fluid in the mixture improved doping of other heteroatoms in addition to silicon during the carbonization process. This result is also consistent with the product yield data obtained for the SiPNDC material which are higher than PNDC (Table 1).
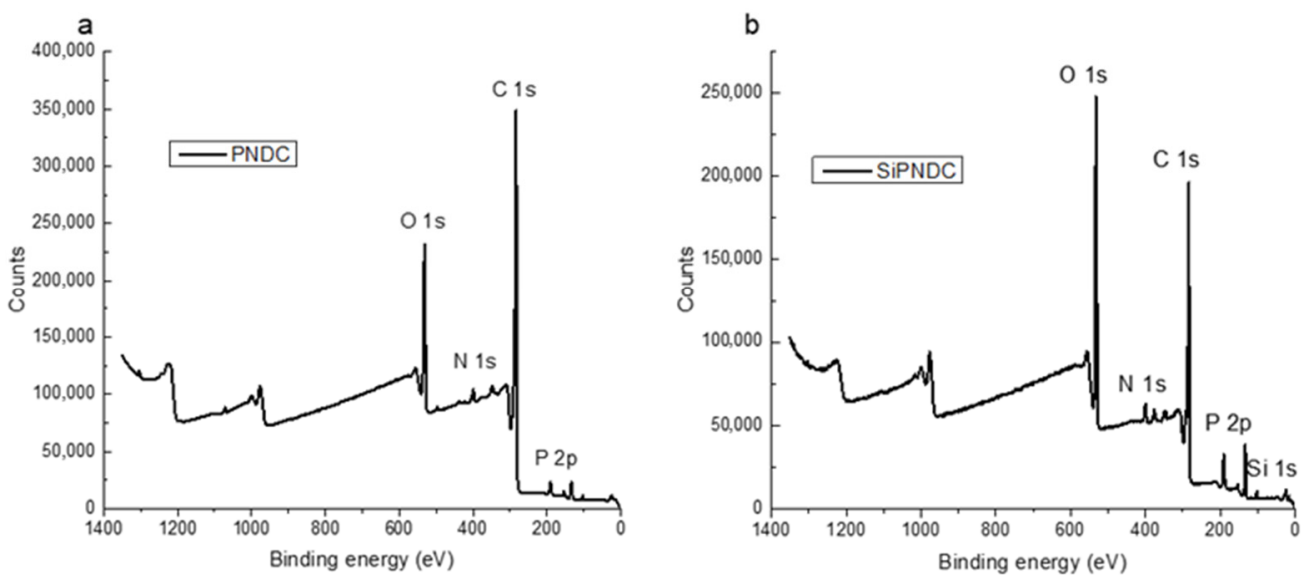

Figure 3. XPS survey scans of (a) PNDC and (b) SiPNDC materials.

Table 3. Surface elemental composition of PNDC and SiPNDC materials from XPS.

\begin{tabular}{ccc}
\hline Element & PNDC (At \%) & SiPNDC (At \%) \\
\hline C 1s & 71.4 & 47.5 \\
O 1s & 20.3 & 36.4 \\
N 1s & 3.4 & 4.0 \\
P 2p & 4.9 & 8.5 \\
Si 1s & - & 4.0 \\
\hline
\end{tabular}

XPS narrow scan data were collected in order to investigate details on the bonding environments of the elements at the electrocatalyst surface (Figures S2 and S3). Four differ- 
ent carbon environments were found to exist in both PNDC and SiPNDC, shown by peaks fitted at 284.8, 286.3, 287.9, and $289.2 \mathrm{eV}$ (Table S1). These peaks correspond to graphitic $\left(\mathrm{sp}^{2}\right)$ carbon, $\mathrm{C}-\mathrm{O} / \mathrm{C}-\mathrm{N}, \mathrm{C}=\mathrm{O} / \mathrm{C}=\mathrm{N}$, and $\mathrm{O}-\mathrm{C}=\mathrm{O}$ bonds, respectively $[10,41,42]$. Both materials contain a mostly graphitic carbon environment. However, SiPNDC contains a lesser percentage composition of graphitic carbon due to its possession of more oxygen and nitrogen functionalities compared to PNDC. Two additional peaks were observed for SiPNDC at 292.9 and $295.7 \mathrm{eV}$ which could be due to $\pi-\pi^{*}$ satellite and residual potassium impurity. Potassium occurs naturally in molasses, so it is possible for a small amount to remain post-carbonization. Deconvolution of O1s peaks reveal three bonding environments of oxygen correlating to quinone $(531.4 \mathrm{eV})$, carbonyl $(533.1 \mathrm{eV})$, and $\mathrm{C}-\mathrm{O}(536.0 \mathrm{eV})$ bonding $[43,44]$. Oxygen bonding in PNDC is primarily due to quinone and carbonyl functional groups while SiPNDC contains a large majority of carbonyl bonding at the surface. Three peaks were determined from deconvolution of nitrogen, namely pyridinic, graphitic/quaternary, and N-oxide bonding environments corresponding to 399.1, 401.9, and $404.8 \mathrm{eV}$, respectively [10,45]. Both PNDC and SiPNDC exhibit mostly graphitic nitrogen bonding at the surface. Phosphorus resulted in two peaks for both PNDC and SiPNDC at 133.8 and $136.9 \mathrm{eV}$ which are correlated to $\mathrm{P}-\mathrm{O}-\mathrm{C}$ (bridging oxygen) and $\mathrm{P}=\mathrm{O}$ bonding [46]. An additional high energy peak at $137.5 \mathrm{eV}$ was shown for SiPNDC.

Raman spectroscopy was performed to determine the degree of defect on the PNDC and SiPNDC materials. Two distinct bands around 1345 and $1580 \mathrm{~cm}^{-1}$ were observed for both materials, corresponding to the disordered band ( $\mathrm{D}$ band) and the graphitic band ( $G$ band). The D and G bands were fitted with Lorentzian model and the D/G ratio is calculated from the area under the curve (Figure 4). The $\mathrm{D}$ band is associated with the breathing mode of defected $\mathrm{sp}^{2}$ carbon rings and occurs as a result of co- or tri-doping with various heteroatoms [47]. The $\mathrm{G}$ band occurs due to in-plane stretching of $\mathrm{sp}^{2}$ carbons [48]. The $\mathrm{D} / \mathrm{G}$ ratio describes the extent of defect or disorder in the carbon materials [49]. PNDC and SiPNDC exhibit similar spectra and D/G ratios with PNDC having a slightly more defected structure.
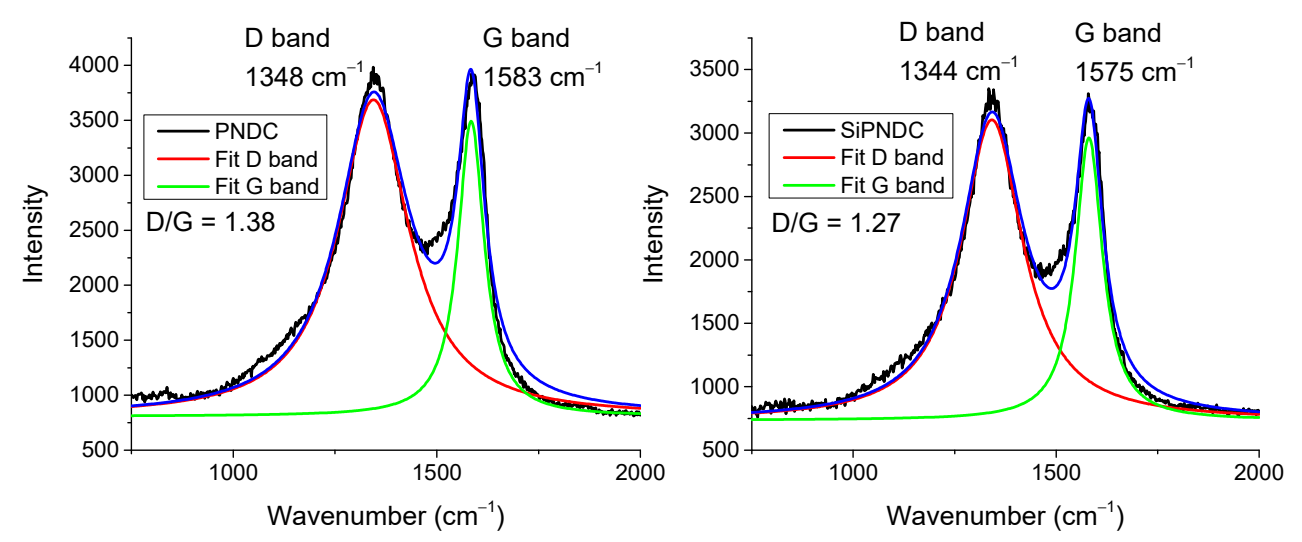

Figure 4. Raman spectra of PNDC and SiPNDC.

\subsection{Electrochemical Performance}

Cyclic voltammograms were recorded for both samples at $100 \mathrm{mV} / \mathrm{s}$ in alkaline media and both exhibited an approximate rectangular shape under an inert environment $\left(\mathrm{N}_{2}\right.$ saturated) (Figure 5). The voltammograms under $\mathrm{O}_{2}$ saturated conditions displayed a prominent reduction peak that is characteristic of ORR. As this peak was only seen under $\mathrm{O}_{2}$ conditions, it can be assumed that PNDC and SiPNDC are able to reduce the dissolved oxygen in solution. The peak reduction potential of PNDC recorded to be $-0.322 \mathrm{~V}$ (vs. $\mathrm{Hg} / \mathrm{HgO}$ ) (Table 4). When tri-doped material was used, the reduction potential shifted to $-0.176 \mathrm{~V}$. The greater positive peak potential of SiPNDC shows a favorable reduction of oxygen as compared to PNDC [23]. This is attributed to an enhanced concentration of doping elements at the surface of SiPNDC as well as greater amount of surface defects. 
The current density is also increased in SiPNDC compared to PNDC, which is due to the high percentage of micropores on SiPNDC surface [50].
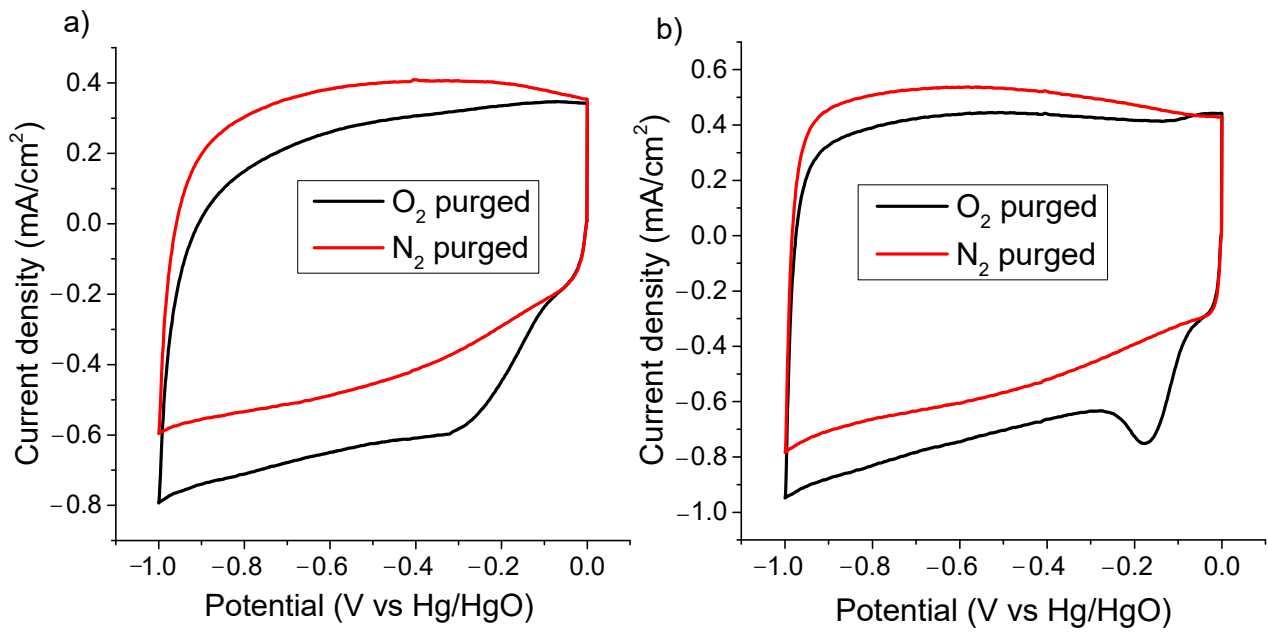

Figure 5. Cyclic voltammograms of (a) PNDC and (b) SiPNDC at $100 \mathrm{mV} / \mathrm{s}$ in $0.1 \mathrm{M} \mathrm{KOH}$ under oxygen and nitrogen saturated environment.

Table 4. Peak oxygen reduction potential (V vs. $\mathrm{Hg} / \mathrm{HgO}$ ) and current density at $100 \mathrm{mV} / \mathrm{s}$ scan rate.

\begin{tabular}{ccc}
\hline Sample & Peak Potential (V vs. Hg/HgO) & Current Density $\left(\mathbf{m A ~ c m}^{-\mathbf{2}}\right)$ \\
\hline PNDC & -0.322 & 0.792 \\
SiPNDC & -0.176 & 1.087 \\
\hline
\end{tabular}

\section{3. $R D E$ and $R R D E$ Studies}

In order to further investigate the mechanism of ORR at doped carbon surface, RDE studies were conducted. RDE measurements allow a direct calculation of the number of electrons involved in the reaction as well as the rate of reaction. Linear sweep voltammograms were generated by rotating a modified glassy carbon electrode at speeds of $100,400,900,1600$, and $2500 \mathrm{rpm}$ at a scan rate of $50 \mathrm{mV} / \mathrm{s}$ in $\mathrm{O}_{2}$ saturated $0.1 \mathrm{M} \mathrm{KOH}$ electrolyte. The onset potential of SiPNDC is recorded to be $-0.08 \mathrm{~V}$ (Figure 6) which is greater than reported values for $20 \% \mathrm{Pt} / \mathrm{C}$ catalyst $(-0.09 \mathrm{~V})$ [19] as well as phosphorus, nitrogen, and fluorine tri-doped graphene $(-0.10 \mathrm{~V})[51]$ and nitrogen doped graphene $(-0.15 \mathrm{~V})$ [52]. Moreover, the current density of SiPNDC is comparable to commercial $20 \%$ $\mathrm{Pt} / \mathrm{C}$ catalyst [19] and nitrogen-doped carbon from aminoterephthalic acid [53].
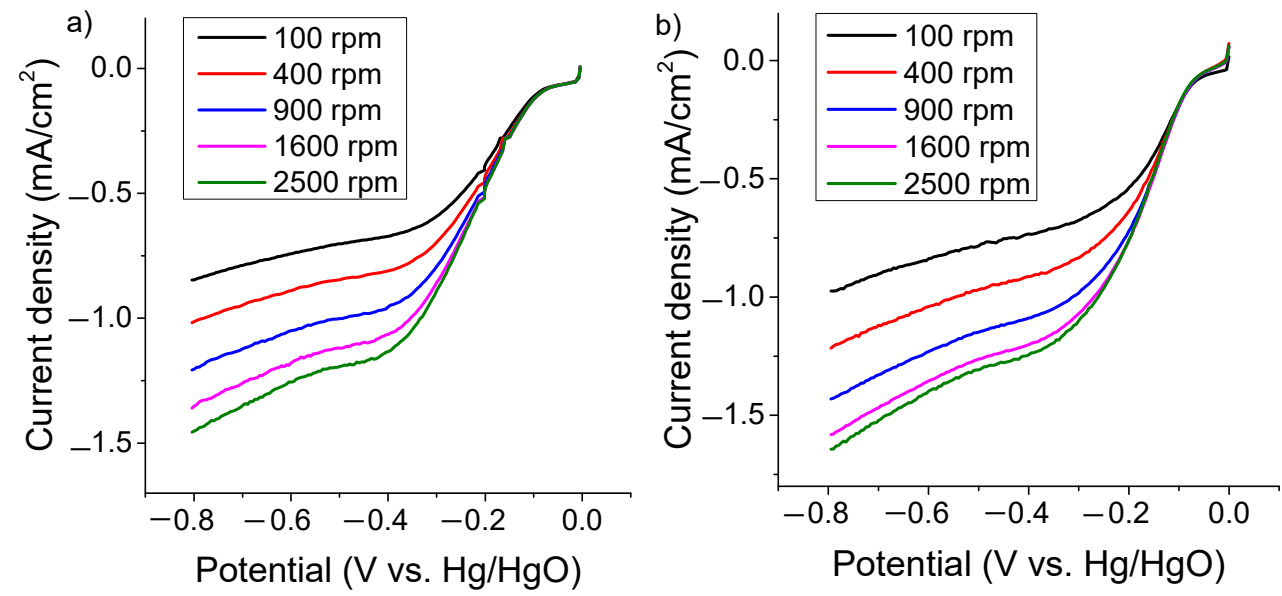

Figure 6. Linear sweep voltammograms at various electrode rotation rates from 100-2500 rpm for (a) PNDC, and (b) SiPNDC at $50 \mathrm{mV} / \mathrm{s}$. 
The generated voltammograms and Koutecky-Levich (K-L) equations (Equations (1) and (2)) were used to make a plot between the reciprocal of the limiting current density $\left(J_{\text {lim }}{ }^{-1}\right)$ versus the reciprocal square root of angular velocity, $\omega(\omega=2 \pi \mathrm{N}$, where $\mathrm{N}$ is linear rotation speed) (Figure 7). From the slope of the K-L plot, the number of electrons involved in the oxygen reduction mechanism are determined (see Table 5) using the following Equations (1) and (2):

$$
\begin{gathered}
J_{\text {lim }}{ }^{-1}=J_{\text {Lev }}{ }^{-1}+J_{k}{ }^{-1} \\
J_{\text {Lev }}=0.620 n F C D^{2 / 3} \omega^{1 / 2} v^{-1 / 6}
\end{gathered}
$$

where $J_{L e v}$ and $J_{k}$ are the Levich current density and the kinetic current density, respectively, $\mathrm{n}$ is the number of electrons, $\mathrm{F}$ is the Faraday constant $\left(96,485 \mathrm{C} \mathrm{mol}^{-1}\right), \mathrm{C}$ is bulk concentration of saturated $\mathrm{O}_{2}\left(1.26 \times 10^{-6}\right)$, $\mathrm{D}$ is the diffusion coefficient of $\mathrm{O}_{2}$ in water $\left(1.9 \times 10^{-5}\right)$, and $v$ is kinematic viscosity of the electrolyte solution $\left(1.1 \times 10^{-2}\right)$. An example calculation is reported in the Supporting Information document. From Table 5 it can be seen that the ORR process at the SiPNDC surface more closely follows a 4-electron process compared to PNDC. This indicates that when PDMS is included in synthesis, the resulting material possesses a greater number of defects and incorporates Si dopants that favor single pathway ORR. Therefore, the tri-doped SiPNDC material is a better performing electrocatalyst for ORR in the fuel cells in comparison to co-doped PNDC. The kinetics of ORR can also be determined by determining the kinetic rate constant $k$ using Equation (3):

$$
J_{k}=10^{3} n F k C \Gamma
$$

where $\Gamma$ is the loading mass of active material on the electrode. The ORR kinetic rate constant is slightly lower for SiPNDC material (Table 5) as compared to PNDC. The wide pore distribution of SiPNDC enhances the ORR reaction but causes the reaction to be slightly more sluggish.

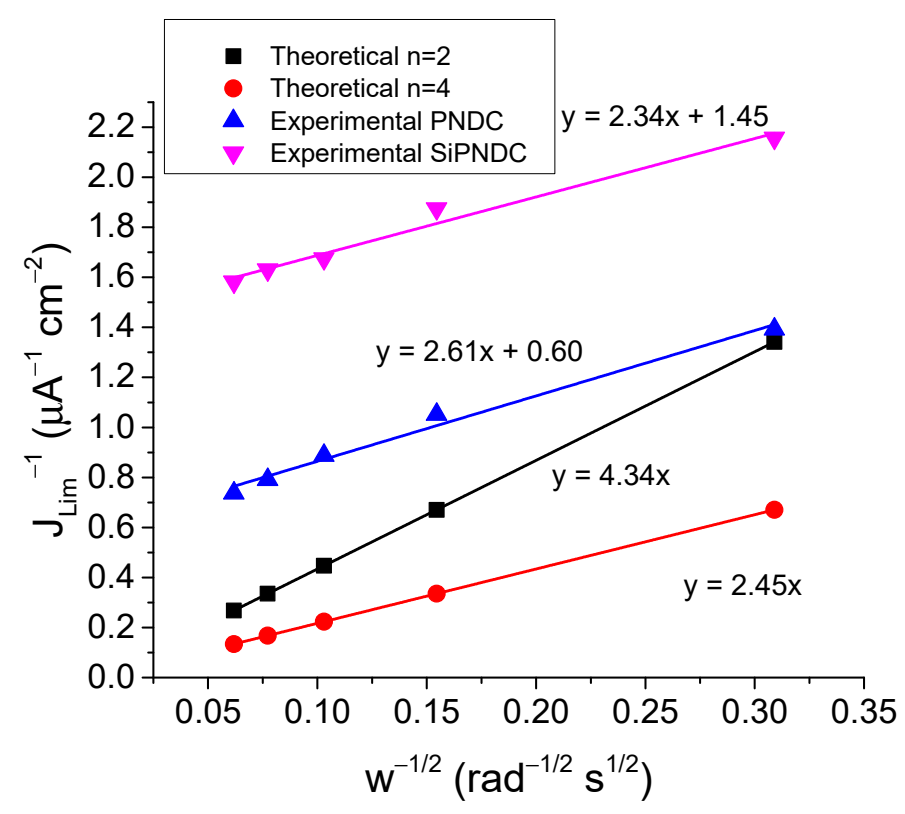

Figure 7. Koutecky-Levich plots and linear fit equations for PNDC, SiPNDC, and theoretical plots for 2-electron and 4-electron processes.

To further investigate the ORR pathway of the doped carbon materials, RRDE studies were conducted. Voltammograms of both materials show very little current generation at the platinum ring indicating that formation of peroxides is minimal for both materials (Figure 8). This is a promising result as peroxide generation is detrimental for electrocatalyst 
performance. This result also confirms the primarily 4-electron pathway of ORR for both PNDC and SiPNDC.
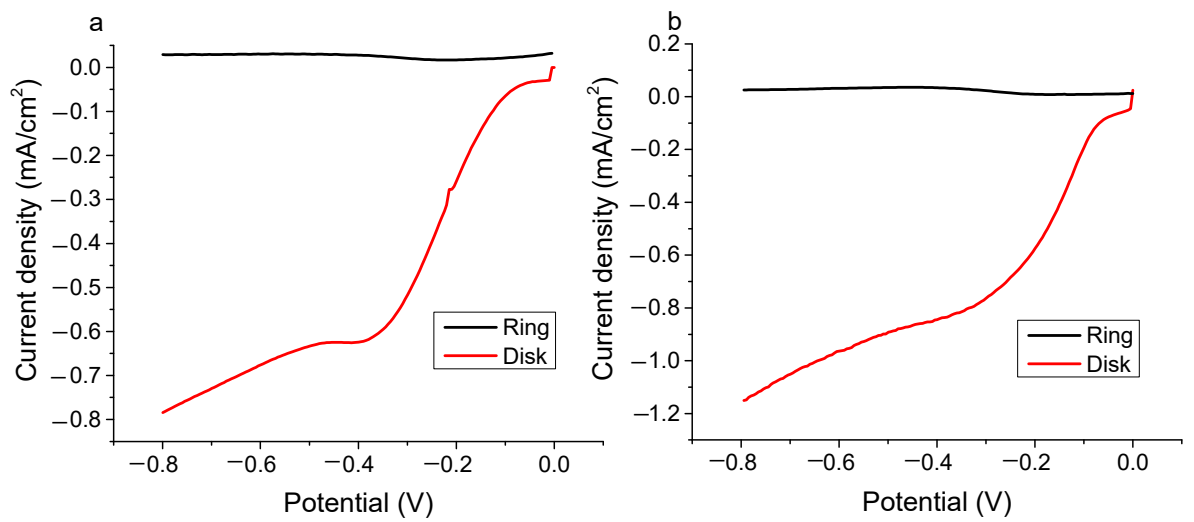

Figure 8. Linear sweep voltammograms of ring vs. disk for (a) PNDC and (b) SiPNDC at $100 \mathrm{rpm}$ and $50 \mathrm{mV} / \mathrm{s}$ sweep rate.

Electrochemical stability is another key parameter when selecting an ORR electrocatalyst for use in fuel cells. Thus, the stability of SiPNDC was examined via continuous cycling over 2500 cycles in $0.1 \mathrm{M} \mathrm{KOH}$ electrolyte saturated with $\mathrm{O}_{2}$. As indicated by Figure 9, the SiPNDC voltammogram retains most of the original current density and ORR peak after continuous cycling, indicating that it is electrochemically stable over that range.

Table 5. Number of electrons and kinetic rate of oxygen reduction via PNDC and SiPNDC.

\begin{tabular}{ccc}
\hline Sample & Average Number of Electrons & Rate $_{\left(\mathbf{m o l}^{-\mathbf{1}} \mathbf{~ s}^{\mathbf{- 1}} \mathbf{)}\right.}$ \\
\hline PNDC & 3.40 & $2.28 \times 10^{2}$ \\
SiPNDC & 3.71 & $0.87 \times 10^{2}$ \\
\hline
\end{tabular}

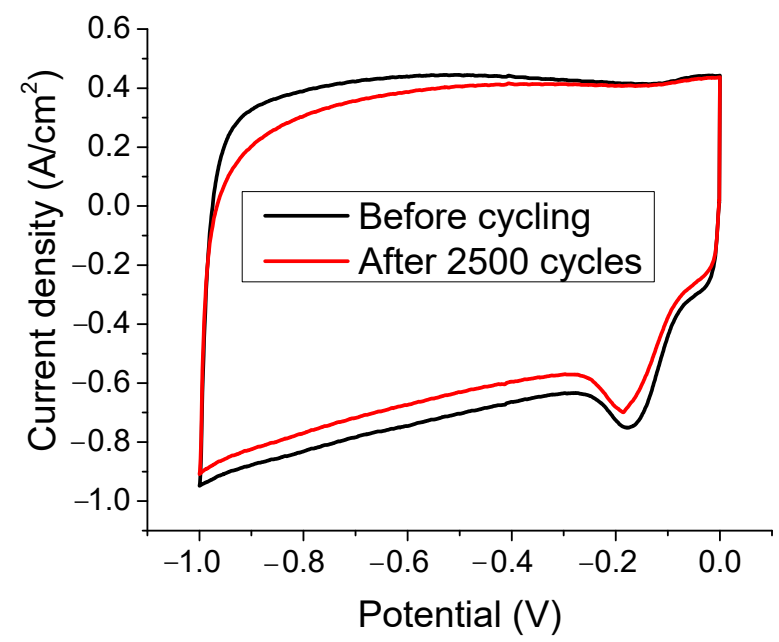

Figure 9. Cyclic voltammograms of $\mathrm{SiPNDC}$ in $\mathrm{O}_{2}$ saturated $0.1 \mathrm{M} \mathrm{KOH}$ at $100 \mathrm{mV} / \mathrm{s}$ over 2500 continuous cycles.

\section{Conclusions}

Both dual and tri-doped carbons were prepared from a renewable plant-based byproduct and their application in fuel cells was demonstrated. The introduction of PDMS enhanced the product yield of SiPNDC compared to dual-doped PNDC. The materials were shown to have similar surface area and porosity characteristics, indicating that surface elements are playing a key role in electrochemical performance of these doped carbon materials. Furthermore, it was found that the introduction of silicon into the PNDC material 
significantly improved the ORR performance of the material by promoting a 4-electron pathway of ORR. Therefore, SiPNDC displayed better electrocatalytic performance due to greater number of defects and enhanced dopant concentration. However, both materials had little to no peroxide formation as confirmed by RRDE experiments proving them to be promising candidates as low-cost and renewable resource-based electrocatalysts.

Supplementary Materials: The following are available online at https:/ / www.mdpi.com/article/10 .3390/electrochem2020022/s1, Figure S1: Pore size distribution of PNDC and SiPNDC; Figure S2: XPS narrow scan plots of C1s, O1s, N1s, and P2p for PNDC material; Figure S3: XPS narrow scan plots of C1s, O1s, N1s, and P2p for SiPNDC material, as well as detailed calculation of number of electrons from RDE.

Author Contributions: Conceptualization, S.M. and N.S.; methodology, S.M., T.V., and N.S.; software, S.M. and N.S.; validation, T.V., F.W., and N.S.; formal analysis, S.M. and F.W.; investigation, N.S.; resources, N.S., F.W., and T.V.; data curation, S.M. and F.W.; writing-original draft preparation, S.M.; writing-review and editing, S.M., T.V., and N.S.; visualization, S.M. and N.S.; supervision, N.S.; project administration, T.V. and N.S.; funding acquisition, N.S. All authors have read and agreed to the published version of the manuscript.

Funding: This research acknowledges the Signature award funding and startup funds from University of Arkansas at Little Rock.

Institutional Review Board Statement: Not applicable.

Informed Consent Statement: Not applicable.

Data Availability Statement: Datasets generated during this study are available from the corresponding author upon reasonable request.

Acknowledgments: The authors would like to thank Shawn Bourdo and Zeid Nima at the Center for Integrative Nanotechnology Sciences at UA Little Rock for the equipment used in physical characterization of the doped carbons. The authors would also like to acknowledge the help of Anindya Ghosh and Bijay Chhetri for their contribution to the electrochemical section of this work.

Conflicts of Interest: The authors declare no conflict of interest.

\section{References}

1. Wang, Y.; Li, L.; Hu, L.; Zhuang, L.; Lu, J.; Xu, B. A feasibility analysis for alkaline membrane direct methanol fuel cell: Thermodynamic disadvantages versus kinetic advantages. Electrochem. Commun. 2003, 5, 662-666. [CrossRef]

2. Kirubakaran, A.; Jain, S.; Nema, R.K. A review on fuel cell technologies and power electronic interface. Renew. Sustain. Energy Rev. 2009, 13, 2430-2440. [CrossRef]

3. Andújar, J.M.; Segura, F. Fuel cells: History and updating. A walk along two centuries. Renew. Sustain. Energy Rev. 2009, 13, 2309-2322. [CrossRef]

4. $\quad$ Spiegel, R.J. Platinum and fuel cells. Transp. Res. Part D Transp. Environ. 2004, 9, 357-371. [CrossRef]

5. Shui, J.; Wang, M.; Du, F.; Dai, L. N-doped carbon nanomaterials are durable catalysts for oxygen reduction reaction in acidic fuel cells. Sci. Adv. 2015, 1, e1400129. [CrossRef] [PubMed]

6. Dicks, A.L. The role of carbon in fuel cells. J. Power Sources 2006, 156, 128-141. [CrossRef]

7. Majidi, M.R.; Shahbazi Farahani, F.; Hosseini, M.; Ahadzadeh, I. Low-cost nanowired $\alpha-\mathrm{MnO}_{2} / \mathrm{C}$ as an ORR catalyst in air-cathode microbial fuel cell. Bioelectrochemistry 2019, 125, 38-45. [CrossRef]

8. Martinaiou, I.; Monteverde Videla, A.H.A.; Weidler, N.; Kübler, M.; Wallace, W.D.Z.; Paul, S.; Wagner, S.; Shahraei, A.; Stark, R.W.; Specchia, S.; et al. Activity and degradation study of an Fe-N-C catalyst for ORR in Direct Methanol Fuel Cell (DMFC). Appl. Catal. B Environ. 2020, 262, 118217. [CrossRef]

9. Wang, D.C.; Huang, N.B.; Sun, Y.; Zhan, S.; Zhang, J.J. GO clad $\mathrm{Co}_{3} \mathrm{O}_{4}\left(\mathrm{Co}_{3} \mathrm{O}_{4} @ G O\right)$ as ORR catalyst of anion exchange membrane fuel cell. Int. J. Hydrogen Energy 2017, 42, 20216-20223. [CrossRef]

10. Chen, Z.; Chen, Z.; Higgins, D. Nitrogen doped carbon nanotubes and their impact on the oxygen reduction reaction in fuel cells. Carbon 2010, 48, 3057-3065. [CrossRef]

11. Liu, Y.H.; Yi, B.; Shao, Z.G.; Xing, D.; Zhang, H. Carbon nanotubes reinforced nafion composite membrane for fuel cell applications. Electrochem. Solid-State Lett. 2006, 9, A356. [CrossRef]

12. Sharma, T.; Mohana Reddy, A.L.; Chandra, T.S.; Ramaprabhu, S. Development of carbon nanotubes and nanofluids based microbial fuel cell. Int. J. Hydrogen Energy 2008, 33, 6749-6754. [CrossRef]

13. Chen, Z.; Higgins, D.; Tao, H.; Hsu, R.S.; Chen, Z. Highly active nitrogen-doped carbon nanotubes for oxygen reduction reaction in fuel cell applications. J. Phys. Chem. C 2009, 113, 21008-21013. [CrossRef] 
14. Zhang, X.; He, W.; Zhang, R.; Wang, Q.; Liang, P.; Huang, X.; Logan, B.E.; Fellinger, T.-P. High-Performance Carbon Aerogel Air Cathodes for Microbial Fuel Cells. ChemSusChem 2016, 9, 2788-2795. [CrossRef]

15. Tardy, G.M.; Lóránt, B.; Lóka, M.; Nagy, B.; László, K. Enhancing substrate utilization and power production of a microbial fuel cell with nitrogen-doped carbon aerogel as cathode catalyst. Biotechnol. Lett. 2017, 39, 993-999. [CrossRef] [PubMed]

16. Guilminot, E.; Fischer, F.; Chatenet, M.; Rigacci, A.; Berthon-Fabry, S.; Achard, P.; Chainet, E. Use of cellulose-based carbon aerogels as catalyst support for PEM fuel cell electrodes: Electrochemical characterization. J. Power Sources 2007, 166, 104-111. [CrossRef]

17. Dhelipan, M.; Arunchander, A.; Sahu, A.K.; Kalpana, D. Activated carbon from orange peels as supercapacitor electrode and catalyst support for oxygen reduction reaction in proton exchange membrane fuel cell. J. Saudi Chem. Soc. 2017, 21, 487-494. [CrossRef]

18. Zhang, E.; Wang, F.; Yu, Q.; Scott, K.; Wang, X.; Diao, G. Durability and regeneration of activated carbon air-cathodes in long-term operated microbial fuel cells. J. Power Sources 2017, 360, 21-27. [CrossRef]

19. Ramasahayam, S.K.; Azam, S.; Viswanathan, T. Phosphorous, nitrogen co-doped carbon from spent coffee grounds for fuel cell applications. J. Appl. Polym. Sci. 2015, 132, 1-8. [CrossRef]

20. Liu, Q.; Chen, C.; Pan, F.; Zhang, J. Highly efficient oxygen reduction on porous nitrogen-doped nanocarbons directly synthesized from cellulose nanocrystals and urea. Electrochim. Acta 2015, 170, 234-241. [CrossRef]

21. Liu, Q.; Chen, S.; Zhou, Y.; Zheng, S.; Hou, H.; Zhao, F. Phosphorus-doped carbon derived from cellulose phosphate as efficient catalyst for air-cathode in microbial fuel cells. J. Power Sources 2014, 261, 245-248. [CrossRef]

22. Liu, Q.; Zhou, Y.; Chen, S.; Wang, Z.; Hou, H.; Zhao, F. Cellulose-derived nitrogen and phosphorus dual-doped carbon as high performance oxygen reduction catalyst in microbial fuel cell. J. Power Sources 2015, 273, 1189-1193. [CrossRef]

23. Ramasahayam, S.K.; Viswanathan, T. Honey-Based P, N and Si Tri-Doped Graphitic Carbon Electrocatalysts for Oxygen Reduction Reaction in Alkaline Conditions. ChemistrySelect 2016, 1, 3527-3534. [CrossRef]

24. Alatalo, S.-M.; Qiu, K.; Preuss, K.; Marinovic, A.; Sevilla, M.; Sillanpää, M.; Guo, X.; Titirici, M.-M. Soy protein directed hydrothermal synthesis of porous carbon aerogels for electrocatalytic oxygen reduction. Carbon 2016, 96, 622-630. [CrossRef]

25. Denmark, I.; Macchi, S.; Watanabe, F.; Viswanathan, T.; Siraj, N. Effect of KOH on the Energy Storage Performance of MolassesBased Phosphorus and Nitrogen Co-Doped Carbon. Electrochem 2021, 2, 29-40. [CrossRef]

26. Siraj, N.; Macchi, S.; Berry, B.; Viswanathan, T. Metal-Free Carbon-Based Supercapacitors-A Comprehensive Review. Electrochem 2020, 1, 410-438. [CrossRef]

27. Macchi, S.; Siraj, N.; Watanabe, F.; Viswanathan, T. Renewable Tannin-Based Dual-Doped Carbon Material and its Application as a Supercapacitor Electrode Material. Curr. Res. Mater. Chem. 2019, 1, 1-7.

28. Ramasahayam, S.K.; Nasini, U.B.; Shaikh, A.U.; Viswanathan, T. Novel tannin-based Si, P co-doped carbon for supercapacitor applications. J. Power Sources 2015, 275, 835-844. [CrossRef]

29. Quílez-Bermejo, J.; Morallón, E.; Cazorla-Amorós, D. Metal-free heteroatom-doped carbon-based catalysts for ORR. A critical assessment about the role of heteroatoms. Carbon 2020, 165, 434-454. [CrossRef]

30. Singh, S.K.; Takeyasu, K.; Nakamura, J. Active Sites and Mechanism of Oxygen Reduction Reaction Electrocatalysis on NitrogenDoped Carbon Materials. Adv. Mater. 2019, 31, 1804297. [CrossRef]

31. Liang, B.; Li, K.; Liu, Y.; Kang, X. Nitrogen and phosphorus dual-doped carbon derived from chitosan: An excellent cathode catalyst in microbial fuel cell. Chem. Eng. J. 2019, 358, 1002-1011. [CrossRef]

32. Chowdhury, C.; Datta, A. Silicon-Doped Nitrogen-Coordinated Graphene as Electrocatalyst for Oxygen Reduction Reaction. J. Phys. Chem. C 2018, 122, 27233-27240. [CrossRef]

33. Liu, Z.; Fu, X.; Li, M.; Wang, F.; Wang, Q.; Kang, G.; Peng, F. Novel Silicon-Doped, Silicon and Nitrogen-Codoped Carbon Nanomaterials with High Activity for the Oxygen Reduction Reaction in Alkaline Medium. J. Mater. Chem. A 2015, 3, 3289-3293. [CrossRef]

34. Ramasahayam, S.K.; Nasini, U.B.; Bairi, V.; Shaikh, A.U.; Viswanathan, T. Microwave Assisted Synthesis and Characterization of Silicon and Phosphorous Co-Doped Carbon as an Electrocatalyst for Oxygen Reduction Reaction. RSC Adv. 2014, 4, 6306-6313. [CrossRef]

35. Gao, S.; Wei, X.; Liu, H.; Geng, K.; Wang, H.; Moehwald, H.; Shchukin, D. Transformation of Worst Weed into N-, S-, and P-Tridoped Carbon Nanorings as Metal-Free Electrocatalysts for the Oxygen Reduction Reaction. J. Mater. Chem. A 2015, 3, 23376-23384. [CrossRef]

36. Tao, X.; Zhang, Q.; Li, Y.; Lv, X.; Ma, D.; Wang, H.G. N, P, S Tri-Doped Hollow Carbon Nanosphere as a High-Efficient Bifunctional Oxygen Electrocatalyst for Rechargeable Zn-Air Batteries. Appl. Surf. Sci. 2019, 490, 47-55. [CrossRef]

37. Macchi, S.; Siraj, N.; Watanabe, F.; Viswanathan, T. Renewable-Resource-Based Waste Materials for Supercapacitor Application. ChemistrySelect 2019, 4, 492-501. [CrossRef]

38. Viswanathan, T. Doped-Carbon Composites, Synthesizing Methods and Applications of the Same. U.S. Patent 9,643,165, 9 May 2017.

39. Sing, K.S.W.; Everett, D.H.; Haul, R.A.W.; Moscou, L.; Pierotti, R.S.; Rouquerol, J.; Siemieniewska, T. Reporting physisorption data for gas/solid systems with special reference to the determination of surface area and porosity. Pure Appl. Chem. 1985, 57, 603-619. [CrossRef] 
40. Ramasahayam, S.K.; Hicks, Z.; Viswanathan, T. Thiamine-Based Nitrogen, Phosphorus, and Silicon Tri-Doped Carbon for Supercapacitor Applications. ACS Sustain. Chem. Eng. 2015, 3, 2194-2202. [CrossRef]

41. Chen, X.Y.; Chen, C.; Zhang, Z.J.; Xie, D.; Deng, X.; Liu, J.W. Nitrogen-Doped Porous Carbon for Supercapacitor with Long-Term Electrochemical Stability. J. Power Sources 2013, 230, 50-58. [CrossRef]

42. Jeyabharathi, C.; Venkateshkumar, P.; Rao, M.S.; Mathiyarasu, J.; Phani, K.L.N. Nitrogen-Doped Carbon Black as Methanol Tolerant Electrocatalyst for Oxygen Reduction Reaction in Direct Methanol Fuel Cells. Electrochim. Acta 2012, 74, 171-175. [CrossRef]

43. Zhao, X.; Zhang, Q.; Zhang, B.; Chen, C.M.; Wang, A.; Zhang, T.; Su, D.S. Dual-Heteroatom-Modified Ordered Mesoporous Carbon: Hydrothermal Functionalization, Structure, and Its Electrochemical Performance. Part. Part. Syst. Charact. 2013, 30, 557-564. [CrossRef]

44. Zhao, X.; Wang, A.; Yan, J.; Sun, G.; Sun, L.; Zhang, T. Synthesis and Electrochemical Performance of Heteroatom-Incorporated Ordered Mesoporous Carbons. Chem. Mater. 2010, 22, 5463-5473. [CrossRef]

45. Nasini, U.B.; Gopal Bairi, V.; Kumar Ramasahayam, S.; Bourdo, S.E.; Viswanathan, T.; Shaikh, A.U. Oxygen Reduction Reaction Studies of Phosphorus and Nitrogen Co-Doped Mesoporous Carbon Synthesized via Microwave Technique. ChemElectroChem 2014, 1, 573-579. [CrossRef]

46. Prasad, K.S.; Pallela, R.; Kim, D.M.; Shim, Y. Microwave-Assisted One-Pot Synthesis of Metal-Free Nitrogen and Phosphorus Dual-Doped Nanocarbon for Electrocatalysis and Cell Imaging. Part. Part. Syst. Charact. 2013, 30, 557-564. [CrossRef]

47. Paulus, U.A.; Wokaun, A.; Scherer, G.G.; Schmidt, T.J.; Stamenkovic, V.; Radmilovic, V.; Markovic, N.M.; Ross, P.N. Oxygen Reduction on Carbon-Supported Pt-Ni and Pt-Co Alloy Catalysts. J. Phys. Chem. B 2002, 106, 4181-4191. [CrossRef]

48. Rao, C.V.; Cabrera, C.R.; Ishikawa, Y. In Search of the Active Site in Nitrogen-Doped Carbon Nanotube Electrodes for the Oxygen Reduction Reaction. J. Phys. Chem. Lett. 2010, 1, 2622-2627. [CrossRef]

49. Liu, M.; Gan, L.; Xiong, W.; Xu, Z.; Zhu, D.; Chen, L. Development of $\mathrm{MnO}_{2}$ /Porous Carbon Microspheres with a Partially Graphitic Structure for High Performance Supercapacitor Electrodes. J. Mater. Chem. A 2014, 2, 2555-2562. [CrossRef]

50. Li, Y.; Zhang, D.; Zhang, Y.; He, J.; Wang, Y.; Wang, K.; Xu, Y.; Li, H.; Wang, Y. Biomass-derived microporous carbon with large micropore size for high-performance supercapacitors. J. Power Sources 2020, 448, 227396. [CrossRef]

51. Zhang, J.; Dai, L. Nitrogen, Phosphorus, and Fluorine Tri-doped Graphene as a Multifunctional Catalyst for Self-Powered Electrochemical Water Splitting. Angew. Chem. Int. Ed. 2016, 55, 13296-13300. [CrossRef]

52. Wang, S.; Yu, D.; Dai, L.; Chang, D.W.; Baek, J.B. Polyelectrolyte-functionalized graphene as metal-free electrocatalysts for oxygen reduction. ACS Nano 2011, 5, 6202-6209. [CrossRef] [PubMed]

53. Haque, E.; Zavabeti, A.; Uddin, N.; Wang, Y.; Rahim, M.A.; Syed, N.; Xu, K.; Jannat, A.; Haque, F.; Zhang, B.Y.; et al. Deciphering the role of quaternary $\mathrm{N}$ in $\mathrm{O}_{2}$ reduction over controlled $\mathrm{N}$-doped carbon catalysts. Chem. Mater. 2020, 32, 1384-1392. [CrossRef] 